\title{
Kuhmilchallergie muss nicht sein
}

\author{
Nahrungsmittelallergie bedeutet meist, die entsprechenden \\ Nahrungsmittel komplett meiden zu müssen. Bei einer kindlichen \\ Kuhmilchallergie ist dies nicht so einfach, da die Milch für die Er- \\ nährung essenziell ist. Kann eine Desensibiliserung erfolgreich sein?
}

$\mathrm{K}$ inder mit einer IgE-vermittelten Kuhmilchallergie weisen ein erhöhtes Risiko auf, später weitere Nahrungsmittelallergien und Folgekrankheiten wie Asthma oder allergische Rhinitis zu entwickeln. Glücklicherweise verschwindet die allergische Reaktion auf Kuhmilch bei vielen Kindern bis zum Alter von etwa 5 Jahren von selbst wieder. Was aber tun mit Kindern, die auch nach dem sechsten Geburtstag noch Symptome nach Kuhmilchkonsum zeigen? Römische Allergologen versuchen diese Frage zu beantworten, indem sie 21 Kinder einem 6-monatigen Desensibilisierungsprotokoll unterzogen.

Bei 18 der an der Studie beteiligten Kinder wurde die IgE-vermittelte Kuhmilchallergie durch einen doppelblinden oralen Provokationstest nachgewiesen, in drei Fällen wurde aufgrund einer klaren Anamnese auf den Test verzichtet. Zusätzlich wurden Pricktests durchgeführt und das spezifische IgE im Serum bestimmt. Zur Desensibilisierung erhielten die Kinder initial im Verhältnis $1 \mathrm{zu}$

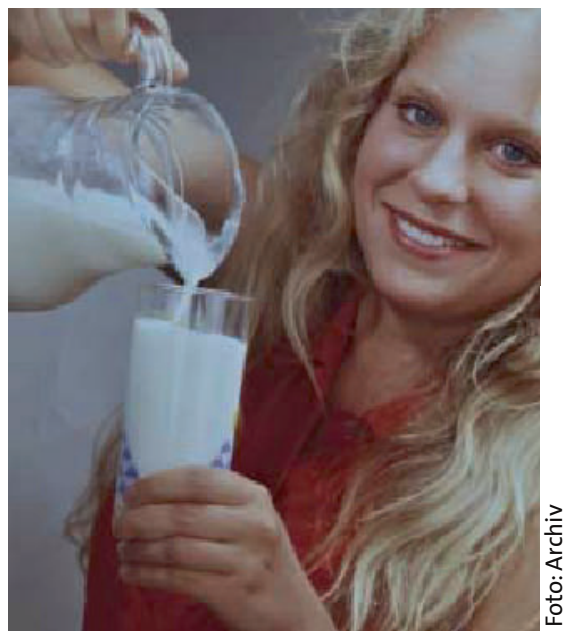

Bei rund $\mathbf{8 0} \%$ der Kinder mit Kuhmilchallergie wachsen sich die Symptome bis ins Jugendlichenalter von selbst aus.
25 mit Wasser verdünnte Kuhmilch. Die Startdosis von 0,06 mg Kuhmilchprotein wurde in den ersten 70 Tagen alle 7 Tag erhöht, dann alle 16 Tage mit dem Endziel einer täglichen Milchzufuhr von $200 \mathrm{ml}$. Zusätzlich erhielten alle Kinder täglich $0,25 \mathrm{mg} / \mathrm{kg}$ Cetirizin. Das Antihistaminikum wurde abgesetzt, sobald die Kinder die maximal tolerierte Milchdosis erreicht hatten.

Nach 6 Monaten hatten 15 der 21 Kinder das Studienziel erreicht und tolerierten $200 \mathrm{ml}$ Kuhmilch pro Tag. Diese Verträglichkeit hielt nach Beendigung der Antihistaminika-Therapie während einer Nachbeobachtungszeit von 2 Monaten an. Drei Kinder vertrugen nach der Desensibilisierung immerhin 40-80 ml Milch pro Tag und waren damit zumindest besser vor schweren Reaktionen durch versehentliche Aufnahme geschützt. Bei weiteren drei Kindern schlug die Therapie nicht an, sie reagierten weiterhin bereits auf geringste Mengen an Kuhmilch mit Symptomen.

Im Pricktest hatte sich die Hautreaktivität gegen Kasein und $\beta$-Laktoalbumin nach 6 Monaten im Mittel signifikant reduziert $(\mathrm{p}<0,001)$. Beim spezifischen IgE gegen Kuhmilch, Kasein und $\beta$-Laktoalbumin ergaben sich keine signifikanten Unterschiede zwischen den Werten vor und nach Desensibilisierung.

Fazit: Durch eine Desensibilisierung mit ansteigenden Milchdosen kann offenbar bei vielen Kindern mit Kuhmilchallergie eine deutlich gesteigerte Toleranz erzielt werden. Weitere Untersuchungen zur Sicherheit und Standardisierung sind aber noch erforderlich.

Meglio $\mathrm{P}$ et al. A protocol for oral desensitization in children with IgE-mediated cow's milk allergy. Allergy 2004; 59: 980-7 